\title{
Reconciling Immersion and Presence: Locative Game Mechanics and Narrative Techniques for Cultural Heritage
}

\author{
Mads Haahr \\ School of Computer Science and Statistics \\ Trinity College, University of Dublin \\ Dublin 2 \\ Ireland \\ Email: mads.haahr@tcd.ie
}

\begin{abstract}
Locative gaming dates back to the early 2000s, and with the success of Ingress (2012) and Pokémon GO (2016), locative games have now entered the mainstream in a very serious way. However, while the genre holds considerable promise for cultural heritage, it has yet to make a real impact for this purpose. A particular challenge is to reconcile the two apparently conflicting concerns of ensuring immersion into the experience without compromising the audience's sense of presence in the physical space. For example, Ingress and Pokémon $G O$ offer excellent immersion in the gameplay but at the cost of near-total loss of the player's sense of presence in the physical environment, even to the extent that accidents occur. For cultural heritage, presence is not only about safety, but also about the audience experiencing the site and not only the digital content. In this paper, we argue that for locative games to be successful for cultural heritage, they must bridge the design tension between offering immersion and presence. We use two of our own titles to shed light on the design concerns and show how careful use of locative game mechanics and narrative techniques can help reconcile these two design pressures and create a new type of engagement with cultural heritage.
\end{abstract}

\section{INTRODUCTION}

Locative gaming dates back to the early 2000s, and with the success of Ingress (2012) and Pokémon GO (2016), locative games have now entered the mainstream in a very serious way. The genre holds considerable potential for cultural heritage sites as a way to present historical and other types of content, and a number of experiences exist, ranging from early experiments such as Geist [19], REXplorer [3] and Viking Ghost Hunt [6] to more mature approaches, such as Jumièges $3 D$ [17]. A study has shown that mobile augmented reality applications with historical pictures and information are of interest to end users and that the level of interest is related to the perceived usefulness and perceived enjoyment of the applications [18].

A considerable challenge of location-based AR games is to offer a sense of immersion into the story/gameplay without losing a sense of presence in the physical space. For example, Pokémon $G O$ excels at the former but fails at the latter, resulting in an experience that draws people into the gameplay at the cost of oblivity to the surroundings, even to the extent that accidents occur due to this loss of presence. While this may be acceptable for a non-cultural game experience, it is unsuitable for site-specific cultural heritage games where the site itself plays a crucial role in the experience.

For cultural heritage, presence is not only about safety, but also about the audience experiencing the site and not only the digital content. In this paper, we argue that for locative games to be successful for cultural heritage, they must bridge the design tension between offering immersion and presence. We use two of our own titles to show how careful use of locative game mechanics, visual and audio design, and narrative techniques can help reconcile these two design pressures to create a new type of engagement with cultural heritage. Rather than being strongly historical, the two games are based on original as well as adapted literary content of particular relevance to the chosen sites.

One title, the award-winning Bram Stoker's Vampires [13], is deployed in Trinity College Dublin in Ireland and engages with the literary heritage of Bram Stoker, who was one of the university's most famous alumni. The paper explains how we reinvented traditional Gothic storytelling techniques, such as fragmented narrative structure and temporal and spatial transgression, for this new medium. The other game, The Amazing Transfabulator [14] is a whimsical time-travel adventure in the spirit of Jules Verne and set in the Victorian Precinct in Oamaru, New Zealand and was developed in collaboration with the local community there. Rather than typical historical (e.g., tourist guide type) experiences, the two titles are intended to offer a more literary type of cultural experience. In the case of Bram Stoker's Vampires, the experience is anchored in the site and its existing literary heritage, and in the case of The Amazing Transfabulator, it is anchored in the existing cultural practices of the local community.

\section{PRESENCE AND IMMERSION}

The term "presence" is often used as an abbreviation of "telepresence," which is an area that has been subject to a considerable amount of research. In this paper, we are concerned with game experiences that take place in real 
cultural heritage sites, as distinct from games that are set in virtual representations of such sites. For this reason, we are not so much interested in telepresence, but rather in what is typically considered a broader notion of presence in the form of a "first order" mediated experience, i.e., the natural way that we as humans experience our surroundings through our natural sensory apparatus, such as sight, hearing, smell, etc. The International Society for Presence Research defines this broader meaning of "presence" as follows:

All experience of the physical world is mediated by the human senses and complex perceptual processes. This experience, identified by some scholars as "first order" mediated experience, is the "normal" or "natural" way we perceive the physical world and provides a subjective sensation of being present in our environment (constituting a broader conception of the term "presence" -- i.e., not a shortened version of "telepresence"). [12]

The term "immersion" is used in game science to describe a particular type of feeling that may be experienced while playing a game. Different types of games have been examined with a view to quantifying immersion, for example first-person shooters [22], however, the experience of immersion is of interest to games more broadly [5]. Brown et al describe immersion during play as "a state facilitated by feelings of empathy and atmosphere" [5, p.81] and observe a correspondence between the highest level of immersion experienced by players with "presence" in the sense of "telepresence," as discussed above (as opposed to the sense in which the term is used in this paper). Ermi et al distinguish between three different types of immersion: sensory, challenged-based and imaginative [10]. Sensory immersion can be intensified with better graphics and sound; challenge-based by engaging gameplay, corresponding roughly to "flow" as described by Csikszentmihalyi [8], [7]; and imaginative immersion as a "game experience in which one becomes absorbed with the stories and the world, or begins to feel for or identify with a game character" [10]. As we will see in this paper, imaginative immersion is the type that is most suited for cultural heritage games that take place in real cultural heritage sites.

\section{RELATED WORK}

The term "locative media" was first used by Karlis Kalnins [2] to describe a test-category of work that originated in the now-defunct Locative Media Lab. Albert also offers the following description:

Locative media art at its best enhances locative literacy. The ability to read, write, communicate is vital for any person needing to act, take power, to have agency. An awareness of how flows and layers of information intersect with and augment a person's locality, and the ability to intervene on this level is a further extension of this literacy, and of their agency. [2]
As pioneers in locative media observed, this linking is ultimately about control-the curative control of the real/virtual mapping. As Farman writes:

What mobile media storytelling projects demonstrate ... is that someone can be staring at a mobile device and be more deeply connected to the space and to others in that space than other people might perceive. Storytelling with mobile media takes the stories of a place and attaches them to that place, offering an almost infinite number of stories that can be layered onto a single site. [11, p.6]

Seminal locative media works from the early and mid 2000s were primarily art projects and research projects; they were experimental systems that drew attention to and helped express spatial relationships. Many were performance-driven and some also intended to be hackable, i.e., allowing modification by the participants. Some developed their story through player engagement with high-activity game mechanics, while others were concerned with a slower story-driven development. In the latter category, history-focused projects, such as Media Portrait of the Liberties [23] and Riot! 1831 [26] explored how media fragments (audio, video and static images) could be situated in locations that were of historical relevance to the story material. As locative media for cultural heritage sites, we consider this placement of media the simplest possible approach; and while it does offer interactivity in terms of navigation of the story space through movement through the site, the level of interactivity with each media fragment is low.

Other projects such as Geist [19], Oakland Cemetery [9] and Carletto the Spider [20] placed more complex entities across cultural sites in the form of virtual storytellers, which allow more interaction than static media fragments. The idea to situate a virtual storyteller in a cultural heritage site is a natural one, because conceptually it represents a straightforward digitization of a familiar entity: the human tour guide. However, while this approach is more sophisticated than static media fragments, it is not how modern games tell stories, and the tour guide abstraction does not lend itself well to what narrative games do best: mystery, exploration, drama and adventure. Except for very short segments, few modern games feature guides who narrate the game's story to the player, because players want to explore themselves. Studies support audiences' desire for interactivity, such as Lombardo et al whose data shows that the users given a virtual guide desire a high degree of interactivity at multiple levels [20, p.18].

A third type of locative media for cultural heritage are actual locative games, such as REXplorer [3] and Viking Ghost Hunt [6], [25] and also the Haunted Planet games discussed later in this paper. Like modern games, which use techniques like environmental storytelling that allow a player to explore a storyworld and piece the snippets together themselves, locative games for cultural heritage can present a narrative as a puzzle to be explored, or solved to different degrees, depending on the players' preferences. This has the advantage that players with different levels of interest in the cultural material can 
delve into it to a degree that is proportional to their interest level.

\section{Locative Game Mechanics}

Game design always involves choosing a collection of "game mechanics," the fundamental interactions through which the players interact with the game. In turn, "gameplay" arises from the game mechanics and the players' interaction with them. For locative games, there is a distinct set of game mechanics known to work well, for example territorial mechanics (related to controlling physical territory) and resource gathering (involving physical movement) as well as collection, levelling and training mechanics (e.g., as known from Pokémon GO and Ingress) [15]. Such mechanics help create a complex gameworld with complex challenges, which in turn extend the duration of the play experience. In game design, extending the duration of the play experience is often seen as desirable, but this is not necessarily so for cultural heritage games. Additionally, increasing the complexity of the game results in a higher level of attention required from the player than a simpler experience, not to mention a steeper learning curve. If we consider the three types of immersion proposed by Ermi et al [10], it is clear that the complex gameworlds offered by Ingress and Pokémon $G O$ offer primarily challengebased immersion. Players are captivated by capturing portals and catching pokémon creatures, not by the sensory fidelity of the experiences. Imaginative immersion also plays a role in these types of games, but the fascination with the stories and worlds of Ingress and Pokémon $G O$ is decidedly secondary to the challenge-based immersion experienced by the player at the time during real-world play. For such games, the attention is easily shifted from the player's immediate surroundings to the gameworld.

For locative cultural heritage games, mechanics like those adopted in Pokémon $G O$ and Ingress are generally unsuited, because they sacrifice presence in the physical space for (challenge-based) immersion into the gameworld. Instead, the best locative game mechanics and gameplay for cultural heritage relate to physical navigation of the site and engagement with gameworld representations of objects of direct relevance to the site itself. For the former, search and scan mechanics in which players find their way through the site using navigational tools, such as maps, radars and dowsing, are particularly useful. For the latter, capture and collection mechanics are helpful, especially if combined with puzzle mechanics that allow the collected game objects to be interacted with (e.g., combined) in order to solve a puzzle or discover a story. The challenges related to navigation and light-weight puzzle-solving result in a type of immersion that reverses the emphasis between challenge-based and imaginative immersion compared to Ingress and Pokémon GO.

In relation to time constraints, it is worth noting that a study by Lombardo et al highlight the importance of spatial as well as temporal constraints in relation to locative cultural heritage games [20]. The game mechanics must take into account the layout of the site, a player's likely journeys through it as well as the duration of the experience, likely as part of a longer visit to the site.

\section{A. Haunted Planet Games}

The Haunted Planet games cast players as paranormal investigators who equipped with paranormal detection devices (smartphones) explore the real world in search for paranormal activity. By collecting and analyzing an increasing body of evidence, players gradually construct the story in their minds and ultimately solve a mystery. In terms of genre, the games fall within the categories of "locally staged treasure hunts" [21, pp.32-34] and "urban adventure games" [21, pp.4244]. Each game contains four "gameplay modes" [1] shown in figure 1, each of which is designed to support particular game mechanics. The play experience consists of a loop containing three tasks-search/exploration, scan/capture and story review-that repeat until the game is finished.

During a typical play experience, the player typically first uses the search/exploration mechanic to discover the location of a paranormal encounter and walk to it. Next, they use the scan/capture mechanic to interact with the encounter. Finally, they review the gathered evidence (photo and story snippet). After this stage, the cycle repeats until there are no more encounters. The games support multiple active encounters at the same time in which case the player chooses which paranormal encounter to walk to. This allows the game's story to branch.

\section{B. Play Modes}

Each game has two modes: site-specific in which it is set in a cultural heritage site using curated geographical points for encounters, and random in which it stages itself to the player's location. In the former configuration, the game is intended as a visitor experience, and in the latter case as a souvenir-an object that can be taken away and used to invoke memories of the visit.

\section{Search/Exploration}

The search/exploration mechanic is facilitated by the Map and Radar game modes shown in figure 1. The Map shows the player's location and an outline of the play area, but not the specific locations of paranormal encounters. The Radar shows a traditional "ship's radar" type view of paranormal encounters in the vicinity but no terrain features. The two modes work in tandem: The Map helps coarse-grained player orientation and the Radar encourages players to explore the site in order to get close to the encounters. As the player approaches an encounter, audio layers are built up to increase dramatic tension [25], [24]. Leaving out the specific locations of encounters from the Map was a deliberate design choice intended to make navigation more challenging and hence more interesting from a gameplay point of view.

\section{Scan/Capture}

The scan/capture mechanic is facilitated by the Ghost Viewer game mode shown in figure 1 . When a player has 

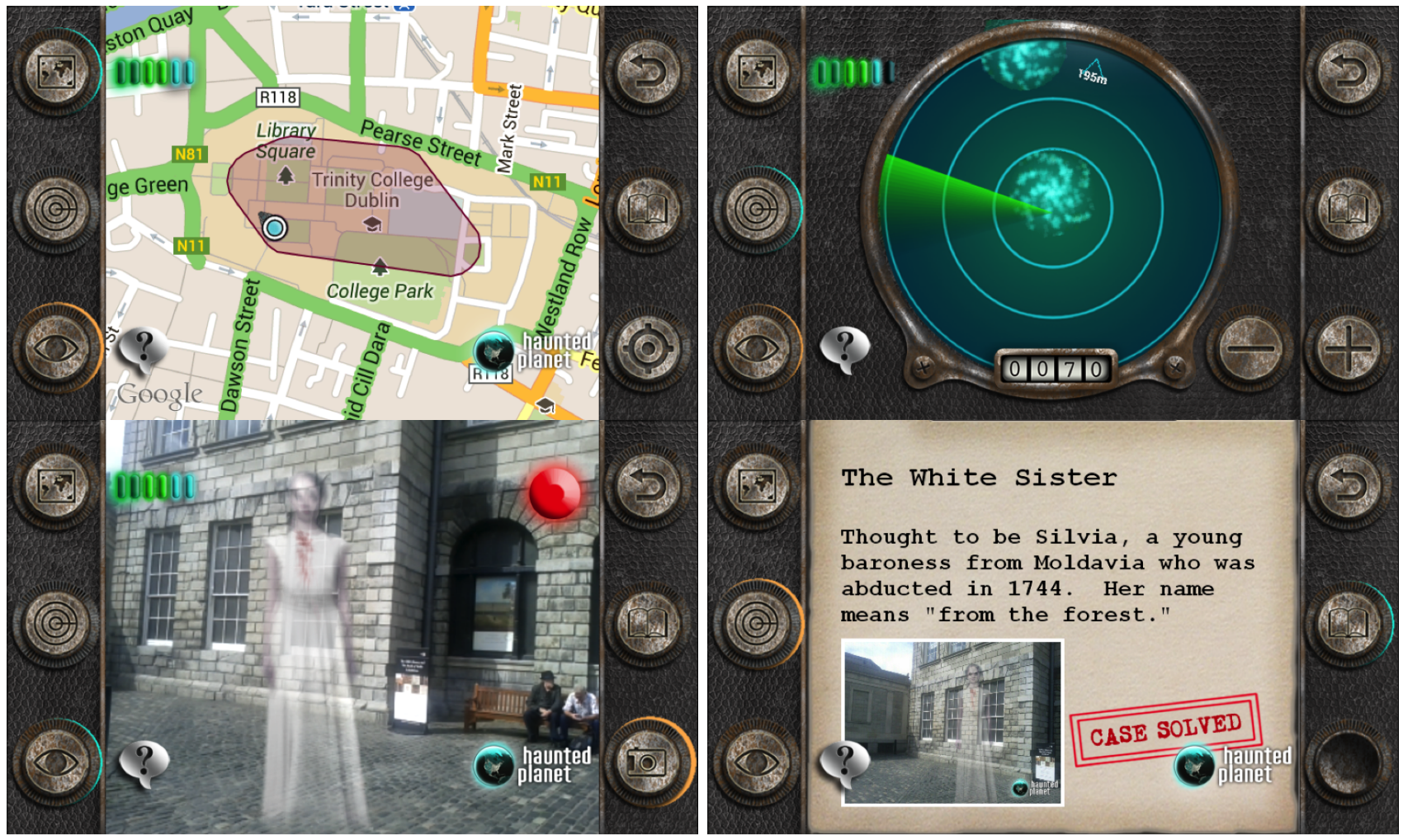

Fig. 1. Gameplay Modes in Bram Stoker's Vampires. From top left: Map, Radar, Ghost Viewer and Casebook. Active mode shown with blue glow.

gotten close to an encounter, they use the Ghost Viewer to scan (using an augmented-reality camera view) their surroundings for visual evidence of paranormal activity and capture it by taking photos. When a character appears on the screen, an entry sound (typically the voice of the character) is triggered. A successful photo is rewarded with extra visual detail in the character and is entered into the Casebook where it unlocks a short piece of background story about the captured character.

\section{E. Story Review}

The last step in the play experience cycle is reviewing the collected evidence. There is no game mechanic associated with this task; the player simply uses the Casebook mode shown in figure 1 to browse the collected evidence and unlocked story snippets. The Casebook serves as a record of the play experience and as a reference to the different characters.

\section{Aesthetics: Visual and Audio Design}

Generally, visual and audio design for games range from abstract to representational [1], where abstract designs have a low degree of realism and representational designs have a high degree of realism. Most locative game experiences have relatively abstract aesthetics, such as the cartoony creatures in Pokémon GO, which by virtue of their design are placed as belonging squarely in the gameworld, not in the physical world. Rather than linking the gameworld with the physical world, these aesthetics result in a clear demarcation between them.
For cultural heritage games, it is more appropriate to develop visual and audio styles that link the gameworld with the physical space, rather than one that only emphasises the former. We have found that photorealistic visuals and audio, such as those shown in figure 2, help create a pretension to veracity that blurs the boundary between the gameworld and physical space and helps the immersion into the former coexist with presence in the latter. By blurring this boundary, we place a certain amount of uncertainty (especially through the use of sound [25]) about where the game objects belong, causing the player to pay extra attention to what is around them. For content that is historical, this approach not only blends the gameworld with the real world, but also mixes the past with the present.

\section{NARRATIVE Structures}

Typical locative games, like Ingress, Pokémon $G O$ and Shadow Cities take "a sandbox approach to narrative, offering a context absent of any inherent plot progression" [15, p.224]. Their narratives are best characterised as frames within which players can develop their own stories as a way to remember certain events. While this works well for game experiences that are intended to be long, it is less suited to game experiences intended to be of definite duration and in which there is a specific story to tell.

For locative cultural heritage games, it is therefore better to consider standard narrative structures, such as branching and decision points. The structures have the advantage that they 

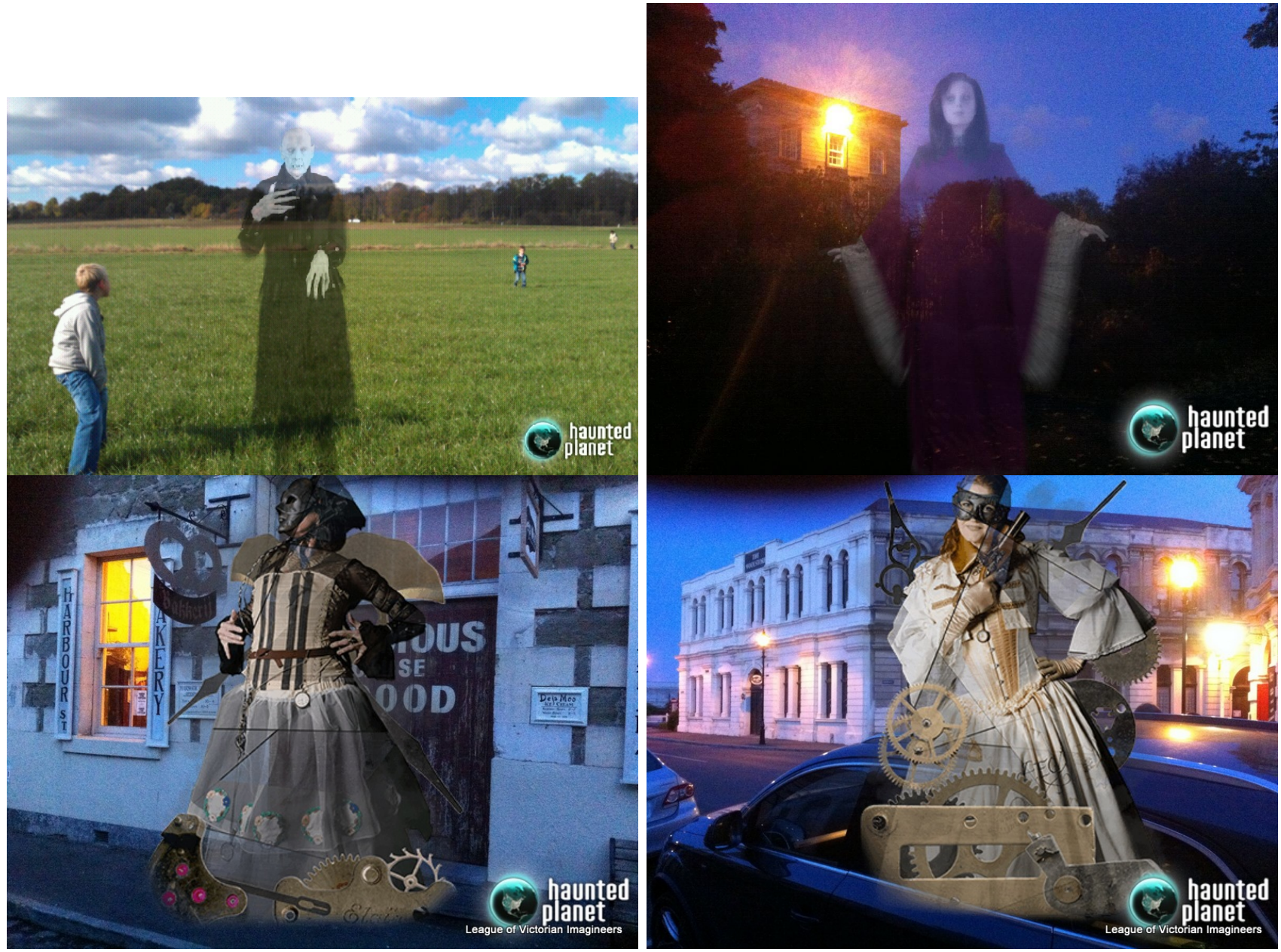

Fig. 2. Player Photos from Bram Stoker's Vampires (top) in random (left) and site-specific (right) mode and The Amazing Transfabulator (bottom) in site-specific mode (left and right).

are immediately familiar to many players, can be made more or less overt in the way they are presented, and that they lend themselves well to being used in physical space. For example, the act of choosing between two branches at a decision point can be a physical act of walking, or choosing between two different destinations within the site. In addition, we have found that certain narrative techniques from genre fiction work well. As we will discuss below, Gothic storytelling often uses temporal and spatial transgressions [16], which can be used to link the past with the present. Similarly, time-travel as known from early science fiction (e.g., H. G. Wells) can also serve as a useful narrative mechanic that allows the past and present to be connected.

Our locative narrative design is heavily inspired by literature, in particular Gothic storytelling, and we have adapted a number of techniques from 18th and 19th century Gothic storytelling to the medium of location-based mobile gaming. Our theoretical starting point is Botting's introduction to the Gothic genre [4]. Under the following headings, we discuss how Gothic narrative methods were adapted for the specific use in our games. We group the features under four headings- setting, narrative structure, temporal transgression and spatial transgression-and discuss how the basic elements in the two games were designed to adapt each particular Gothic feature to the medium of the location-based augmented-reality game.

\section{A. Setting}

The underlying intention of the two games were to serve as new ways to interact with the cultural heritage associated with a particular site. Bram Stoker's Vampires is set in Trinity College Dublin, Ireland, a 16th century university campus in which the author of Dracula was a student 1864-1870. The encounters are placed in areas that the author is known to have frequented and which would have been relevant for his life. When playing the game, the player engages not only with characters from the author's most famous literary work, but also with the space that he inhabited during his formative years.

The Amazing Transfabulator is set in the Victorian Precinct in Oamaru, New Zealand, a town of population 13,650 in which many citizens engage with their Victorian heritage through steampunk - a cultural practice involving arts, crafts, 
festivals and performance in the spirit of fantastical writers such as H.G. Wells and Jules Verne. Our whimsical story of Professor Hürkelheimer and his company of time travellers is well in line with the creative cultural practices of the Oamaru historical enthusiasts and their own use of the Victorian Precinct.

From a narrative perspective, we consider the settings for the two games examples of "[h]eavy historical trappings" [4] so popular with Gothic stories. As settings, the historical College campus and the Victorian Precinct help Gothicize the game's augmented-reality view and the photos collected during play.

\section{B. Narrative Structure}

Botting describes Gothic stories as "tortuous, fragmented narratives relating mysterious incidents, horrible images and life-threatening pursuits" [4], and the form of Dracula is of course deliberately fragmented: The novel consists of diary extracts, medical journal excerpts, personal letters and newspaper clippings. In Bram Stoker's Vampires, we retained structural fragmentation by dividing the narrative into encounters that players experience in a non-linear fashion and must collate in their minds, similarly to the task performed by a reader of Dracula. We further added spatial fragmentation by scattering the fragments across the play area. Hence, the act of recomposing the narrative becomes not only an intellectual but also a physical act.

Although The Amazing Transfabulator is more whimsical in its flavour, the structural and spatial fragmentation resonates well with its story too: A mad professor's time machine has malfunctioned, leaving its motley crew of Victorian time travellers scattered across the historical quarter in Oamaru. In this case, the act of finding the characters becomes a way to re-establish order (at least temporarily) by restoring the time machine to a functional state.

\section{Temporal Transgression}

Botting writes that "Gothic atmospheres ... have repeatedly signalled the disturbing return of pasts upon presents," and Dracula is of course all about the past (Medieval Europe) intruding on the present (Victorian England). Table I shows this in tabular format. In Bram Stoker's Vampires, we retained the temporal transgression of Count Dracula upon the Victorian characters, but replaced Dr Van Helsing with the ghost of Bram Stoker. Consequent changes were made in setting and origin of power, as shown in table II. In addition, we added the present time, facilitating a three-pronged temporal transgression in which the smartphone-carrying player is haunted not only by the vampires, but also by their Victorian author, who is himself haunted by the monsters he created.

As time travellers, the characters from The Amazing Transfabulator are of course also temporal transgressors, even if accidentally so-like the vampires in Stoker's novel, they are characters from a fictional past, intruding on the present. It becomes the player's task to deal with them, even if the result is temporary.

\begin{tabular}{|l|l|l|}
\hline & Middle Ages (MA) & Victorian (V) \\
\hline Character & Count Dracula & Dr Van Helsing \& Co. \\
\hline Setting & Transylvania & London \\
\hline Origin of Power & Occult & Science \\
\hline
\end{tabular}

TEMPORAL TRANSGRESSION In Dracula [27]. TRANSGRESSION HAPPENS $\mathrm{MA} \rightarrow \mathrm{V}$

\begin{tabular}{|l|l|l|l|}
\hline & Middle Ages (MA) & Victorian (V) & Present (P) \\
\hline Character & Count Dracula & Bram Stoker & Player \\
\hline Setting & Transylvania & Dublin & Reality \\
\hline Origin of Power & Occult & Literature & Technology \\
\hline
\end{tabular}

TEMPoral Transgression In Bram Stoker's Vampires. TRANSGRESSION $\mathrm{HAPPENS} \mathrm{MA} \rightarrow \mathrm{V}, \mathrm{MA} \rightarrow \mathrm{P}$ AND $\mathrm{V} \rightarrow \mathrm{P}$

\section{Spatial Transgression}

Botting writes that Gothic storytelling devices "destabilised the boundaries between psyche and reality, opening up an indeterminate zone in which the differences between fantasy and actuality were no longer secure," and Dracula is an excellent example of such "a fiction with pretensions to ... veracity." To help support the player's suspension of disbelief, we designed our character visuals to be photorealistic and to blend beautifully with the backdrop provided by the settings (figure 2) and also adopted a sophisticated mix of real world and game world audio in order to blur the boundary between fact and fiction [25], [24].

\section{CONCLUSION}

This paper has explored the design tension between presence and immersion in locative games for cultural heritage. We used examples of popular locative games Ingress and Pokémon GO and discussed why the designs used in those games are not suited for cultural heritage sites because of their emphasis on challenge-based immersion. Using two of our own titles, we presented examples of game mechanics and narrative techniques that allowed experiences to be based on imaginative immersion, which are intended to offer a reconciliation between presence and immersion that is more suitable for locative games for cultural heritage sites.

\section{ACKNOWLEDGMENT}

The author would like to thank current and former members of the Haunted Planet Studios team, in particular Roisín Cotton, Tara Carrigy, Natasa Paterson Paulberg, Dan Burke, Neil Delaney and Regina de Búrca.

\section{REFERENCES}

[1] Ernest Adams. Fundamentals of Game Design. New Riders, 2010.

[2] Saul Albert. Locative literacy. Mute, 1(28), 2004.

[3] Rafael Ballagas, André Kuntze, and Steffen P Walz. Gaming tourism: Lessons from evaluating rexplorer, a pervasive game for tourists. In International Conference on Pervasive Computing, pages 244-261. Springer, 2008.

[4] Fred Botting. Gothic. The New Critical Idiom, 1995. 
[5] Emily Brown and Paul Cairns. A grounded investigation of game immersion. In CHI '04 Extended Abstracts on Human Factors in Computing Systems, CHI EA '04, pages 1297-1300, New York, NY, USA, 2004. ACM.

[6] Tara Carrigy, Katsiaryna Naliuka, Natasa Paterson, and Mads Haahr. Design and evaluation of player experience of a location-based mobile game. In Proceedings of the 6th Nordic Conference on Human-Computer Interaction: Extending Boundaries, pages 92-101. ACM, 2010.

[7] Mihaly Csikszentmihalyi. The Psychology of the Optimal Experience. Harper Perennial, New York, USA, 1990.

[8] Mihayi Csikszentmihalyi. Beyond Boredom and Anxiety. Jossey-Bass Publishers, San Francisco, USA, 1975.

[9] Steven Dow, Jaemin Lee, Christopher Oezbek, Blair Maclntyre, Jay David Bolter, and Maribeth Gandy. Exploring spatial narratives and mixed reality experiences in oakland cemetery. In Proceedings of the 2005 ACM SIGCHI International Conference on Advances in computer entertainment technology, pages 51-60. ACM, 2005.

[10] Laura Ermi and Frans Mäyrä. Fundamental components of the gameplay experience: Analysing immersion. Worlds in play: International perspectives on digital games research, 37(2):37-53, 2005.

[11] Jason Farman. The Mobile Story: Narrative Practices with Locative Technologies. Routledge, 2013.

[12] International Society for Presence Research. Presence defined, 2000.

[13] Mads Haahr. Bram Stoker's Vampires. Haunted Planet Studios, 2012.

[14] Mads Haahr. The Amazing Transfabulator. Haunted Planet Studios, 2013.

[15] Mads Haahr. Everting the holodeck. In Hartmut Koenitz, Gabriele Ferri, Mads Haahr, Diğdem Sezen, and Tonguç İbrahim Sezen, editors, Interactive Digital Narrative: History, Theory and Practice, chapter 14, pages 211-226. Routledge, 2015.

[16] Mads Haahr. Literary play: Locative game mechanics and narrative techniques for cultural heritage. In Joint International Conference on Serious Games, pages 114-119. Springer, 2015.

[17] Didier Happe and Gael Hamon. Jumièges 3D. Departement de la SeineMaritime, 2013.

[18] Anne-Cecilie Haugstvedt and John Krogstie. Mobile augmented reality for cultural heritage: A technology acceptance study. In Mixed and Augmented Reality (ISMAR), 2012 IEEE International Symposium on, pages 247-255. IEEE, 2012.

[19] Ursula Kretschmer, Volker Coors, Ulrike Spierling, Dieter Grasbon, Kerstin Schneider, Isabel Rojas, and Rainer Malaka. Meeting the spirit of history. In Proceedings of the 2001 Conference on Virtual Reality, Archeology, and Cultural Heritage, pages 141-152. ACM, 2001.

[20] Vincenzo Lombardo and Rossana Damiano. Storytelling on mobile devices for cultural heritage. New Review of Hypermedia and Multimedia, 18(1-2):11-35, 2012.

[21] Markus Montola, Jaakko Stenros, and Annika Waern. Pervasive Games: Theory and Design. Morgan Kauffman, 2009.

[22] Lennart Nacke and Craig A. Lindley. Flow and immersion in first-person shooters: Measuring the player's gameplay experience. In Proceedings of the 2008 Conference on Future Play: Research, Play, Share, Future Play '08, pages 81-88, New York, NY, USA, 2008. ACM.

[23] Valentina Nisi, Ian Oakley, and Mads Haahr. Location-aware multimedia stories: Turning spaces into places. In Proceedings of ARTECH Conference, pages 72-93. Universidade Cátolica Portuguesa, 2008.

[24] Natasa Paterson, Gavin Kearney, Katsiaryna Naliuka, Tara Carrigy, Mads Haahr, and Fionnuala Conway. Viking ghost hunt: Creating engaging sound design for location-aware applications. International Journal of Arts and Technology, 6(1):61-82, 2013. Inderscience.

[25] Natasa Paterson, Katsiaryna Naliuka, Søren Kristian Jensen, Tara Carrigy, Mads Haahr, and Fionnuala Conway. Design, implementation and evaluation of audio for a location aware augmented reality game. In Proceedings of the 3rd International Conference on Fun and Games, pages 149-156. ACM, 2010.

[26] Josephine Reid. Design for coincidence: Incorporating real world artifacts in location based games. In Proceedings of the 3rd International Conference on Digital Interactive Media in Entertainment and Arts, pages 18-25. ACM, 2008.

[27] Bram Stoker. Dracula. Archibald Constable and Company, 1897. 